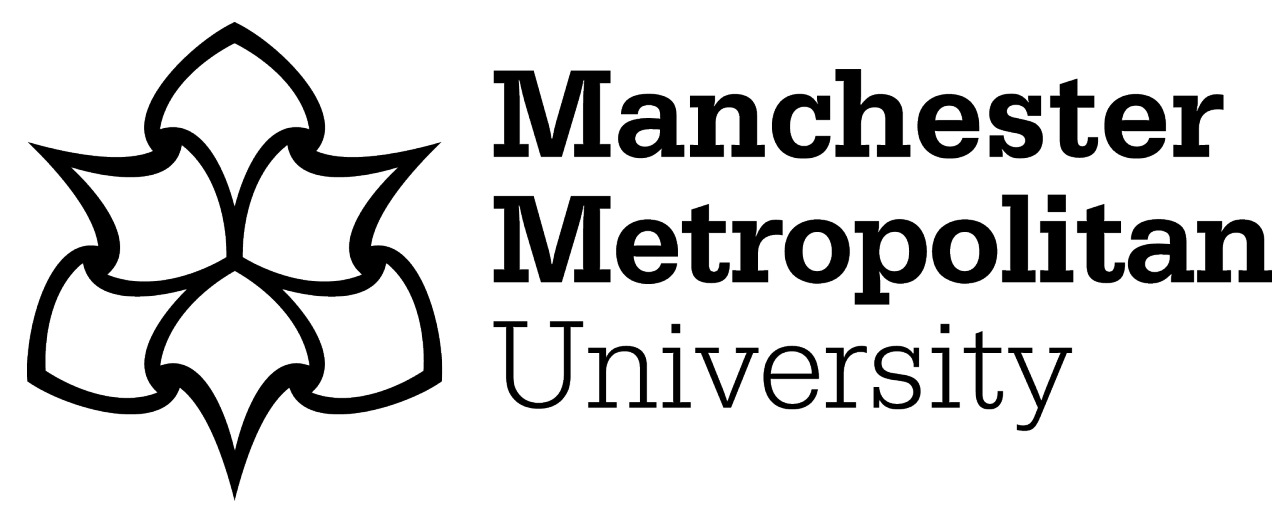

Ahsan, Mominul, Stoyanov, Stoyan and Bailey, Chris (2016) Prognostics of automotive electronics with data driven approach: A review. In: 2016 39th International Spring Seminar on Electronics Technology (ISSE), 18 May 2016 - 22 May 2016, Pilsen, Czech Republic.

Downloaded from: https://e-space.mmu.ac.uk/624875/

Publisher: IEEE

DOI: https://doi.org/10.1109/isse.2016.7563205

Please cite the published version 


\title{
Prognostics of Automotive Electronics with Data Driven Approach: A Review
}

\author{
Mominul Ahsan, Stoyan Stoyanov and Chris Bailey \\ Computational Mechanics and Reliability Group, University of Greenwich, London, UK \\ Email: m.ahsan@greenwich.ac.uk
}

\begin{abstract}
Prognostics and Health Management (PHM) is a comprehensive framework that can deal with solutions for predicting and maintaining electronic system's health. The emerging concept of PHM is increasingly considered for adoption in many engineering fields such as automotive, mechanical, electrical, industrial, aerospace and railway. PHM of electronic components and systems can offer competitive advantages by improving performance, reliability, safety, maintainability and availability. In this paper, a brief description of PHM concept, current PHM approaches, key prognostics components and corresponding monitored/sensed parameters in automotive PHM applications are presented. Software tools developed for PHM applications are also reviewed. Particular focus is given on data driven approaches for prognostics of performance and reliability of automotive electronic systems. Based on the undertaken review of state-of-art in this area, key requirements and attributes of prognostic frameworks for automotive electronics are formulated and future prognostics challenges for the sector are discussed.
\end{abstract}

\section{INTRODUCTION}

Prognostics and Health Management (PHM) is a dynamic discipline of technologies and methods to solve reliability and maintainability problems of a component or system [1-4]. Prognostic techniques have the ability to forecast degradation of a component or system as well as provide appropriate maintenance strategy by evaluating present condition of the system. PHM is a methodology used to measure and forecast reliability of engineering products in order to avoid the risk of sudden failure.

PHM research is motivated and driven by increasing demand for condition based maintenance of systems to reduce the cost of maintenance and to mitigate the risk of failure and unavailability. Predicting the reliability of the products/systems requires the identification, integration and efficient numerical implementation of suitable PHM diagnostic and prognostic techniques. The continuing increase in the use of sensors and the availability of large amounts of measured performance data in modern automotive electronics make the adoption and use of data-driven PHM approach very appealing. There is still a need to fully understand and convey the advantages and disadvantages of the various PHM strategies in relation to the automotive electronics application. In a vehicle, prognostic and diagnostic information helps taking suitable actions and managing the operation and use of electronics components. The information can be used in predicting the likelihood of future sudden failure of any component during its operation. Furthermore, the manufacturer can also receive information through prognostic techniques to evaluate the vehicle performance. Thus, the ability to identify maintenance schedule for a vehicle before a catastrophic failure takes place can help reducing and controlling unnecessary maintenance costs. The realisation process of PHM involves a number of steps and expected outputs that altogether results in PHM capability for the components of a system of interest (Fig. 1).

Data driven approach offers widespread product coverage. It is suitable for complex and highly integrated systems in prognostics of automotive applications. The system can be easily employed for prognostics purposes without prior knowledge. The system also performs precise operations to solve technical difficulties and reduces maintenance and repair costs. Therefore, data driven approach is a very 
convenient and powerful way to realise prognostics capabilities in automotive electronics. In such applications, data driven approach is predominantly considered as a result of the extensive use of sensors and the comprehensive monitoring and recording of data from the electronic components/systems.

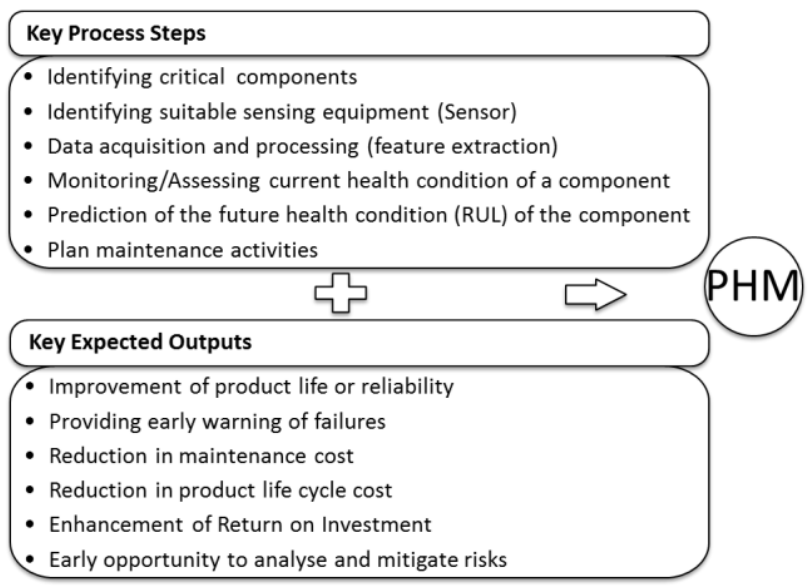

Fig. 1. Presents the key process steps and expected outcomes in PHM.

The main requirements of the PHM in condition based monitoring and maintenance are capabilities that ensure failure prevention, extended operational life of the products, improved reliability, operational and maintenance cost effectiveness, and availability of remaining useful life estimations $[5,6]$. This paper provides overview and discussions on different PHM approaches, and in particular focusing on the data driven approach for prognostics of automotive electronics applications.

\section{Prognostic Approaches}

Fault diagnosis and prognosis (FDP) has three major paradigms: model based, data-driven based and fusion/hybrid based (Fig. 2) [7]. The model-based approach uses a mathematical representation of a system. Therefore, it incorporates a physical understanding of the system into the monitoring scheme [7]. The knowledge about the relationship between measurements, design parameters and the degradation trends to derive functional or physical models are established and then used with this approach. Models can be developed at both micro and macro levels. The identification of model parameters and states enables an exact assessment of the monitored indicator and related uncertainties (model errors, measurements errors, bandwidth of operating conditions).

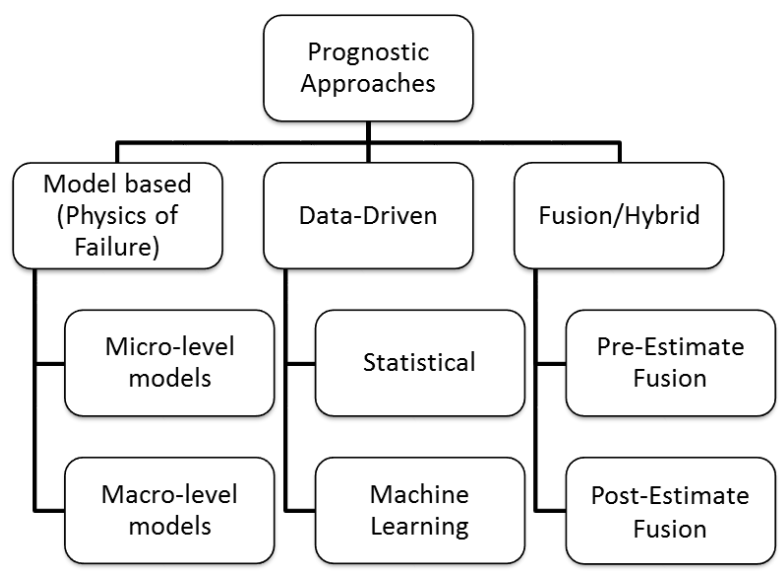

Fig. 2. Different prognostic approaches $[1,7,8]$.

The data driven approach can realise predictions for remaining useful life (RUL) through statistical and probabilistic methods [8]. The approach is used to identify a suitable damage propagation model utilising collected information about the degradation path and relevant operating conditions to identify a suitable damage propagation model. It is then possible to predict the future state of the system using mathematical models, weight parameters etc., which are considered and derived based on the training data under various usage conditions. Data driven approach describes different characteristics and future behaviours based on the trend of data found with the indicative parameters for the state and health of the system [9]. Statistical and machine learning techniques are used typically to detect the changes of component performance and degradation.

Data fusion/hybrid approach uses the strategy to combine the strengths from data and model driven approaches to provide an optimised prognostics solution in an accurate way [10]. This approach first detects failure mechanisms, critical components and monitoring parameters using the data driven approach. Model based approach is used to access the product damage. RUL of the product can be estimated by combining the model results and anomaly trending from data driven approach $[1,7,11]$.

\section{Prognostics in Automotive Electronics}

Automotive systems have become more critical and increased dependency on advanced computing systems that enable detection and future life 
predictions of respective components. Currently, several research initiatives are looking into the prognostics of automotive electronics based on the data-driven and model-based approaches.

\subsection{Major prognostics components in automotive electronic}

Today's modern automotive vehicles have become more complex and increasingly dependent on a huge number of electronic systems for the ease of control in operation. However, at the same time, the inclusion of a higher number of electronic systems increases the chances of operational failure in the automotive cars due to any fault or failure taking place in them. Therefore, it is important to have the knowledge of electronic systems for fault diagnosis and prognosis. Fig. 3 highlights some of the important electronic parts or systems used in automotive cars such as electronic throttle control, battery management, antilock braking, active suspension, onboard diagnostics etc.

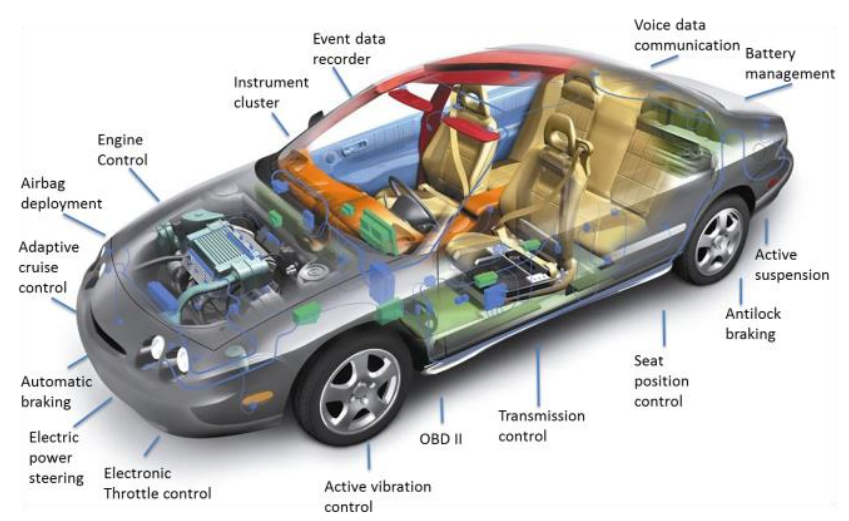

Fig. 3. Typical electronic components and systems in an automotive car [12].

\subsection{Monitoring parameters of automotive electronics}

In the literature, a number of studies have been conducted on the prognosis of electronic systems in automotive cars [13, 14]. Table 1 provides some examples of prognostics parameters that have been used in automotive PHM. For example, the bending curvature of a PCB was monitored using strain gauges from the responses of the PCB under vibration loading, which were used to calculate the interconnect strain values [15]. Damage assessment was conducted by inputting the strain values in a vibration failure fatigue model. RUL was predicted using the damage estimates accumulated using Miner's rule.
Table 1. Summary of prognostics parameters on PHM of automotive electronics

\begin{tabular}{|c|c|c|c|}
\hline $\begin{array}{l}\text { Part/Product/ } \\
\text { System }\end{array}$ & $\begin{array}{l}\text { Measured/ } \\
\text { Monitored } \\
\text { Parameters }\end{array}$ & $\begin{array}{l}\text { Diagnosis/ } \\
\text { Prognosis } \\
\text { Output }\end{array}$ & Ref. \\
\hline $\begin{array}{l}\text { Printed circuit } \\
\text { board (PCB) }\end{array}$ & Frequency & $\begin{array}{l}\text { Damage } \\
\text { accumulation } \\
\text { and RUL }\end{array}$ & [15] \\
\hline $\begin{array}{l}\text { LI-ION } \\
\text { Batteries }\end{array}$ & $\begin{array}{l}\text { Depth of } \\
\text { discharge } \\
\text { (DOD) }\end{array}$ & $\begin{array}{l}\text { State of charge } \\
\text { (SOC), state of } \\
\text { health }(\mathrm{SOH}), \\
\text { and RUL }\end{array}$ & [16] \\
\hline $\begin{array}{l}\text { Regenerative } \\
\text { braking system }\end{array}$ & $\begin{array}{l}\text { Battery charge, } \\
\text { motor speed, } \\
\text { motor current } \\
\text { and wheel } \\
\text { torque }\end{array}$ & Fault diagnosis & [17] \\
\hline Semiconductor & Resistance & $\begin{array}{l}\text { Damage and } \\
\text { RUL }\end{array}$ & [18] \\
\hline Power Window & $\begin{array}{l}\text { Torque rate state } \\
\text { and angular } \\
\text { velocity } \\
\text { measurements }\end{array}$ & $\begin{array}{l}\text { Pinch } \\
\text { conditions and } \\
\text { safety } \\
\text { precautions }\end{array}$ & [19] \\
\hline
\end{tabular}

\subsection{Data driven prognostics in automotive electronics}

Data-driven approaches (Fig. 4) are underpinned by machine learning or statistical methods [20-23]. A machine learning approach uses measured or sensor data to estimate and calculate the current status of a system's health as well as predict the future health condition. Although a lot of historical failure data is required in the statistical method, it is relatively easy to implement owing to the availability of wellestablished technology related to this method.

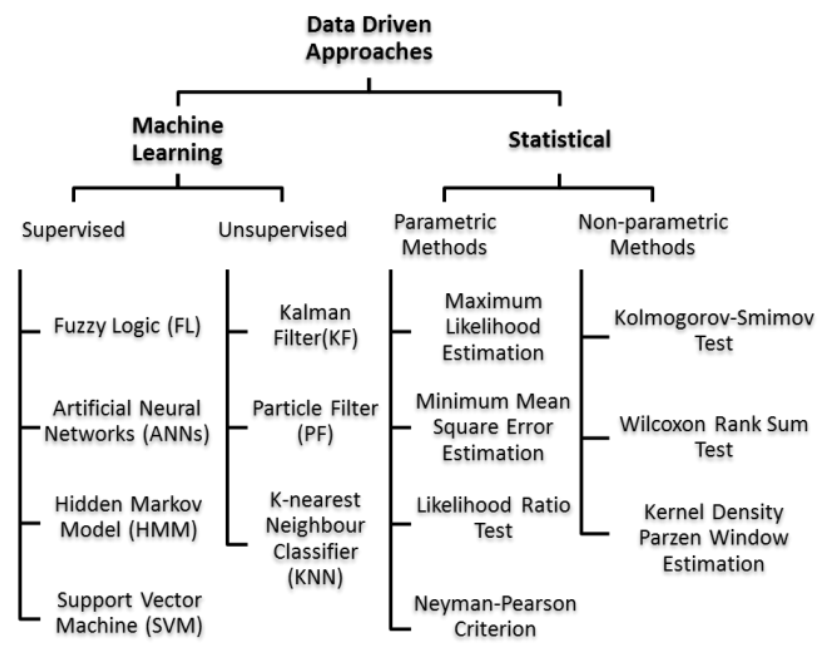

Fig. 4. Data-driven prognostic approaches [20]. 
Examples of data driven prognostics algorithms applied in prognostics of automotive components/ systems are presented in Table 2.

Table 2. Summary of data driven prognostics algorithms on automotive components/systems

\begin{tabular}{|c|c|c|c|c|}
\hline $\begin{array}{l}\text { Parts/ } \\
\text { Products } \\
\text { /Systems }\end{array}$ & $\begin{array}{l}\text { Detection/ } \\
\text { Measurement }\end{array}$ & Output & $\begin{array}{l}\text { Algorithms } \\
\text { (see Fig. 4) }\end{array}$ & Ref \\
\hline Battery & Charge & $\begin{array}{l}\text { State of } \\
\text { health } \\
\text { (SOH) and } \\
\text { RUL }\end{array}$ & $\begin{array}{l}\text { Dempster- } \\
\text { Shafer theory } \\
\text { (DST) and the } \\
\text { Bayesian } \\
\text { Monte Carlo } \\
\text { (BMC) } \\
\text { method }\end{array}$ & $\begin{array}{l}{[24,} \\
25]\end{array}$ \\
\hline $\begin{array}{l}\text { Antilock } \\
\text { braking }\end{array}$ & Fault & $\begin{array}{l}\text { Better } \\
\text { diagnostic }\end{array}$ & $\begin{array}{l}\text { model-based } \\
\text { and data- } \\
\text { driven } \\
\text { techniques } \\
\text { (SVM) }\end{array}$ & $\begin{array}{l}{[26,} \\
27]\end{array}$ \\
\hline $\begin{array}{l}\text { Electric } \\
\text { Power } \\
\text { Steering }\end{array}$ & $\begin{array}{l}\text { Measurement, } \\
\text { detection and } \\
\text { isolation of } \\
\text { faults }\end{array}$ & $\begin{array}{l}\text { Simulate } \\
\text { nominal and } \\
\text { faulty } \\
\text { scenarios }\end{array}$ & $\begin{array}{l}\text { model-based } \\
\text { and data- } \\
\text { driven } \\
\text { approach } \\
\text { (SVM, PNN } \\
\text { and KNN) }\end{array}$ & [28] \\
\hline $\begin{array}{l}\text { Electro- } \\
\text { lytic } \\
\text { Capacitor }\end{array}$ & $\begin{array}{l}\text { Uncertainty is } \\
\text { pursued to } \\
\text { process noise, } \\
\text { sensitivity } \\
\text { analysis }\end{array}$ & RUL & $\begin{array}{l}\text { Particle filter } \\
(\mathrm{PF})\end{array}$ & [29] \\
\hline
\end{tabular}

\subsection{Software tools in automotive prognostics}

More recently, a number of software tools are developed for diagnosis and prognosis of machine fault, predicting the RUL, condition based maintenance and maintenance scheduling of automotive electronics components [30]. Table 3 presents few examples of software tools developed for the prognostics of automotive electronics.

\section{Proposed Prognostics APPROACh FOR AUTOMOTIVE ELECTRONICS}

Based on the current knowledge about PHM available in the literature, it is identified that achieving high-level prognostics accuracy in an integrated and automated way is still an issue. Given the identified key requirements and attributes of a prognostic framework, a generic structure for development and realisation of PHM approach for automotive electronics is proposed (Fig. 5).
Table 3. List of software tool for PHM of automotive electronic parts/systems

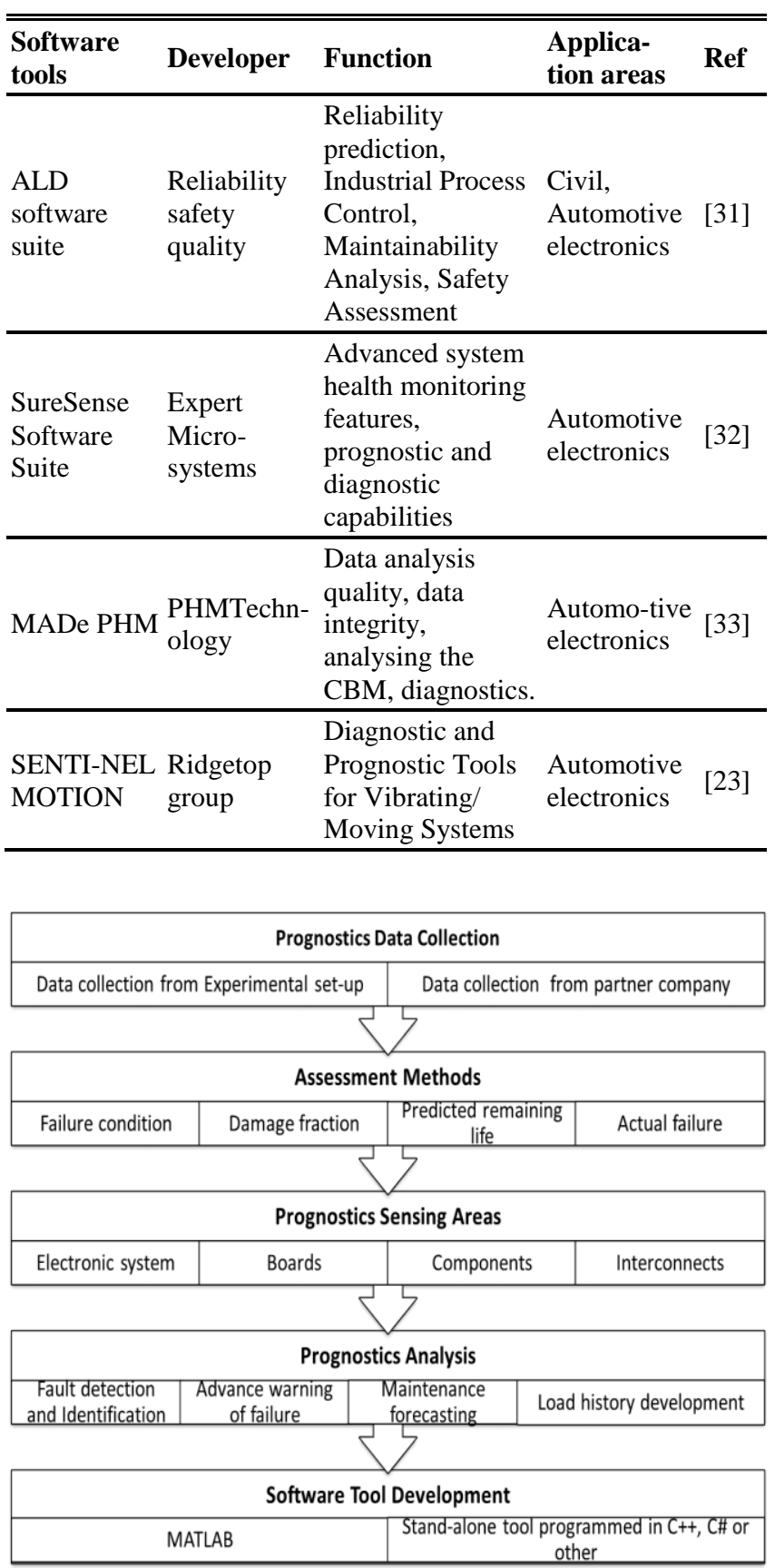

Fig. 5. A proposed framework of PHM intelligent system development.

The proposed PHM framework integrates data driven approach for automotive electronics and is based on the deployment of a wide range of data collection, signal processing and assessments of failure condition, damage fraction, actual failure as well as future life. The approach analyses the sensed 
data to detect the fault and assess the system's health by providing advance warning of failure and maintenance forecasting. Furthermore, a software tool has been planned to develop for automated prognosis and making maintenance decision.

\section{SUMmARY AND Future OUTLOOK}

The paper summarised the current state of PHM for automotive electronics. A comparison among different prognostics approaches based on their performance, advantages and disadvantages has been discussed. The review identified a number of commonly used monitoring parameters such as temperature, voltage, current, vibration, resistance, altitude etc. for the diagnostics and prognostics of performance and reliability of automotive electronic components and systems. Common data driven algorithms that are found to be used for in the prognostics of automotive parts/systems such as engine, battery, antilock braking systems include neural networks, fuzzy logic and different Bayesian methods. The capability and functionality of PHM software tools for automotive electronics such as ALD software suite, MADe PHM, I-CAIV® etc. have been also reviewed. Based on current developments in the field, a generic framework for the prognostics of automotive electronics has been formulated and proposed.

Despite PHM developments over the past years, there are still many challenges, particularly in relation to automotive electronics PHM. For example, there is a need for improving the computational techniques so that they can deal and process with a high volume of data and become more accurate. Application of PHM in prediction outcomes from qualification tests is an emerging research topic aiming to help reduction of product qualification times and optimise test procedures. Another challenge is the dealing with unexpected new faults of automotive electronic components as these clearly cause difficulties in predicting RUL [34]. Furthermore, it is expected that in future research focus would be concentrated on establishing complete PHM with accuracy rather than simply detecting faults [35]. The proposed conceptual data driven PHM framework for the automotive electronic system in this paper (Fig. 5) aims to define the key PHM elements that can help in addressing the current challenges and issues.

\section{REFERENCES}

[1] Pecht, M., and Jaai, R., "A prognostics and Health Management Roadmap for Information and Electronics-rich Systems", Microelectronics Reliability, Vol. 50, No. 3, 2010, pp. 317-323

[2] Long, B., Wang, H., Miao, Q. and Pecht, M., "A Prognostics and Health Management Strategy for Complex Electronic Systems", Prognostics \& System Health Management Conference, Beijing, China, 2012, pp. 287-302

[3] Lee, J., Wu, F., Zhao, W., Ghaffari, M. and Liao, L., "Prognostics 101: Prognostics and Health Management Design for Rotary Machinery Systems-Reviews, methodology and applications" Mechanical Systems and Signal Processing, vol. 42, no. 1-2, 2014, pp. 314-334

[4] Lebold M, Reichard K, Boylan D. "Utilizing DCOM in an Open System Architecture Framework for Machinery Monitoring and Diagnostics". IEEE Aerospace conference, vol. 3; 2003. p. 1227-36.

[5] Peng, Y., Dong, M. and Zuo, M.J., "Current Status of Machine Prognostics in Condition Based Maintenance: a review", Int Journal Advanced Manufacturing Technology, Vol. 50, pp. 297-313, 2010

[6] Jardine, A.K.S., Lin, D. and Banjevic, D., "A Review on Machinery Diagnostics and Prognostics Implementing Condition Based Maintenance", Mechanical System and Signal Processing, Vol. 20, 2006, pp. 1483-1510

[7] Braden, D. and Harvey, D., "A Prognostic and Data Fusion Based Approach to Validating Automotive Electronics," SAE Technical Paper 2014-01-0724, January, 2014, pp. 1-7

[8] Kabir, A. Bailey, C., Lu, H. and Stoyanov, S. "A Review of Data-driven Prognostics in Power Electronics," Electronics Technology (ISSE), 2012 35th International Spring Seminar on, Bad Aussee, 2012, pp. 189-192.

[9] Sankavaram, C., Kodali, A., Ayala, D.F.M., Pattipati, K., Sing, S. and Bandyopadhyay, P., "Event-driven Data Mining Techniques for Automotive Fault Diagnosis", 21st International Workshop on the Principles of Diagnosis, Portland, Oregon, 2010, pp. 1-8

[10] Mikat, H., Siddiolo, A. M., and Buderath, M., "Development of Diagnostics \& Prognostics for Condition-Based Decision Support", Second European Conference of the Prognostics and Health Management Society, vol. 5 no. 41, 2014, pp. 1-16

[11] Salunkhe, T., Jamadar, N.I. and Kivade, S.B., "Prediction of Remaining Useful Life of Mechanical Components-A Review", International Journal of Engineering Science and Innovative Technology (IJESIT), vol. 3, no. 6, 2014, pp. 125 - 135

[12] Anon, http://www.cvel.clemson.edu/auto/ systems/ auto-systems.html (Accessed on June 2015) 
[13] Ismail, A. and Jung, W. "Recent Development of Automotive Prognostics", Korean Reliability Society, Incheon, South Korea, 2015, pp. 147-153

[14] Abbas, M., Ferri, A. A., Orchard, M. E. and Vachtsevanos, G. J. "An Intelligent Diagnostic/Prognostic Framework for Automotive Electrical Systems", IEEE Intelligent Vehicles Symposium, Istanbul, Turkey, 2007, pp. 352 - 357

[15] Gu, J., Lau, D. and Pecht, M., (2009) "Health Assessment and Prognostics of Electronic Products", 8th International Conference on Reliability, Maintainability and Safety, Chengdu, China, 2009, pp. $912-919$

[16] Sankavaram, C., Pattipati, B., Kodali, A., Pattipati, K., Azam, M., Kumar, S. and Pecht, M. "ModelBased and Data-Driven Prognosis of Automotive and Electronic Systems", IEEE International Conference on Automation Science and Engineering, Bangalore, India, 2009, pp. 96 - 101

[17] Sankavaram, C., Pattipati, B., Pattipati, K., Zhang, Y. and Howell, M. "Fault Diagnosis in Hybrid Electric Vehicle Regenerative Braking System", IEEE Access, vol. 2, 2014, pp. 1225 - 1239

[18] Mishra, S., Pecht, M. and Goodman, D. L. "In-situ Sensors for Product Reliability Monitoring", The International Society for Optical Engineering (SPIE), vol. 4755, 2002, pp. $10-19$

[19] Ra, W. S., Lee, H. J., Park, J.B. and Yoon, T. S., "Practical Pinch Detection Algorithm for Smart Automotive Power Window Control Systems", IEEE Transactions on Industrial Electronics, vol. 55, no. 3, 2008, pp. $1376-1384$

[20] Zhang H., Kang R. and Pecht, M. "A hybrid Prognostics and Health Management Approach for Condition-Based Maintenance", IEEE International Conference on Industrial Engineering and Engineering Management, 2009, pp. 1165-1169

[21] Wang, M. H., Chao, K. H., Sung, W.T. and Huang, G.J., "Using ENN-1 for Fault Recognition of Automotive Engine", Expert Systems with Applications, Vol. 37, No. 4, 2010, pp. 2943-2947

[22] Antory, D., “Application of a Data-Driven Monitoring Technique to Diagnose Air Leaks in an Automotive Diesel Engine: A Case Study", Mechanical Systems and Signal Processing, Vol. 21, No. 2, 2007, pp. 795-808

[23] Anon, "Prognostic and Health Management Solutions for Electronic Systems", Ridgetop group, http://www.ridgetopgroup.com/products/advanceddiagnostics-and-prognostics/sentinel-suite-familyof-advanced-diagnostics-and-prognostics-tools/ (accessed June 2015)

[24] Meissner, E. and Richter, G., "The Challenge to the Automotive Battery Industry: The Battery Has Become an Increasingly Integrated Component
Within the Vehicle Electric Power System", Journal of Power Sources, Vol. 144, No. 2, 2005, pp. 438460

[25] Wei H., Williard, N., Osterman, M. and Pecht, M., "Prognostics of Lithium-ion Batteries Based on Dempster-Shafer Theory and The Bayesian Monte Carlo Method", Journal of Power Sources, Vol. 196, No. 23, 2011, pp. 10314-10321

[26] Luo, J., Namburu, M., Pattipati, K, Qia, L. and Chigusa, S., "Integrated Model-Based and DataDriven Diagnosis of Automotive Anti-lock Braking Systems", IEEE System, Man, and Cybernetics Part A: Systems and Humans IEEE Transactions on, vol. 40, no. 2, 2010, pp.321-336

[27] Sankavaram, C., Pattipati, B., Pattipati, K., Zhang, Y., Howell, M. and Salman, M. "Data-Driven Fault Diagnosis in a Hybrid Electric Vehicle Regenerative Braking System", IEEE Aerospace Conference, Big Sky, MT, USA, 2012, pp. $1-11$

[28] Ghimire, R., Sankavaram, C., Ghahari, A., Pattipati, K., Ghoneim, Y., Howell, M. and Salman, M., "Integrated Model-Based and Data-Driven Fault Detection and Diagnosis Approach for an Automotive Electric Power Steering System," IEEE AUTOTESTCON, 2011, pp.70-77

[29] Rigamonti, M., Baraldi, P., Zio, E., Astigarraga, D. and Galarza, A. "Particle Filter-Based Prognostics for an Electrolytic Capacitor Working in Variable Operating Conditions," IEEE Transactions on Power Electronics, vol. 31, no. 2, February 2016, pp. 1567-1575

[30] Asmai, S. A., Hussin, B., Yusof, M. M. "A Framework of an Intelligent Maintenance Prognosis Tool." IEEE Second International Conference on Computer Research and Development, 2010, pp. 241-245

[31] Anon, "Safety and Reliability Analysis Software", ALD Reliability and Safety Tools, http://aldservice.com/ / (accessed June 2015)

[32] Anon, "Predictive Asset Health Management ${ }^{\circledR}$ Software", Expert Microsystems, http://expmicrosys. com/solutions/suresense-suite/ / (accessed June 2015)

[33] Anon, "Software Tool for PHM Capability", PHMTechnologie http://www.phmtechnology.com /products/made-phm.html (accessed April 2015)

[34] Zhang, Y., Gantt, G.W., Rychlinski, M. J., Edwards, R. M., Correia, J. J., Wolf, C.E. "Connected Vehicle Diagnostics and Prognostics, Concept, and Initial Practice". IEEE Transactions on Reliability, vol. 58, no. 2, 2009, pp. 286-294

[35] Byttner, S., Rögnvaldsson, T., Svensson, M. "Consensus Self-organized Models for Fault Detection (COSMO)". Eng. Appl. Artif. Intel. vol. 24 no. 5, 2011, 833-839 